\title{
Effect of diabetes on the sugar nucleotides in several tissues of the rat
}

\author{
M.J.Spiro \\ Department of Medicine, Harvard Medical School and the Elliott P. Joslin Research Laboratory, Joslin Diabetes Center, \\ Boston, Massachusetts, USA
}

\begin{abstract}
Summary. Studies have been carried out to determine the effect of diabetes on the concentrations of sugar nucleotides in several tissues of the rat. This represents one aspect of an investigation aimed at evaluating the role which alterations in the metabolism of glycoproteins or other glycoconjugates may play in the development of the long-term complications of this disease. Measurements were made of the nucleotides of hexoses, $\mathrm{N}$-acetylhexosamines, hexuronic acids, and sialic acid in liver, kidney, skeletal muscle, testis and heart of alloxan-diabetic rats and age-matched controls. Of the intermediates studied, only UDP-glucose and UDP-galactose showed significant alterations in diabetes. The direction of the changes depended on the tissue, with the levels in liver and skeletal muscle being decreased, those in kidney and testis increased and the concentrations in heart being unchanged. In the diabetic liver, the concentrations of UDP-glucose was reduced to
\end{abstract}

0.75 that of normal, while in skeletal muscle both UDP-glucose and UDP-galactose were significantly decreased (diabetic to normal ratios of 0.67 and 0.64 , respectively). Kidney and testis, on the other hand, showed elevations of both UDP-glucose and UDP-galactose, with the diabetic levels being 1.2 to 1.3 those of normal levels. The direction of change in UDPglucose in a tissue appeared to reflect its known ability to synthesize glycogen in diabetes. The finding of elevated UDPglucose and UDP-galactose concentrations in diabetic kidney is considered to be potentially of great importance to the increased synthesis of basement membrane collagen by this tissue.

Key words: Sugar nucleotides, UDP-glucose, UDP-galactose, basement membrane synthesis, glycoproteins.
In recent years, studies of the long-term complications in diabetes have dealt increasingly with alterations in the metabolism of carbohydrate-containing macromolecules. Among the glycoconjugates studied have been the capillary basement membranes, which have been found to thicken in many tissues in diabetes [1] and to show increased synthesis in the kidney [2-4]; glycosaminoglycans, for which abnormal synthesis [5-7] or reduced levels [8] have been reported; serum glycoproteins, several of which have been found in increased concentrations in diabetes [9]; and material believed to be glycoprotein in nature which has been observed in both dog and human hearts in diabetes $[10,11]$. Moreover, a distinction has been made between the unimpaired synthesis of glycoproteins by diabetic liver and its markedly reduced glycogen formation $[12,13]$.

Since the synthesis of these carbohydrate-containing molecules may be controlled to some extent by the levels of their sugar nucleotide precursors, it is important to know what effect the diabetic state may have on the concentrations of these compounds. In the present study, measurements have been made of the nucleotide derivatives of the hexoses, the $\mathrm{N}$-acetylhexosamines, the hexuronic acids and of sialic acid. The tissues investigated included those requiring insulin for glucose entry or phosphorylation, as well as those which appear to be independent of insulin for their handling of this sugar.

\section{Materials and methods}

Studies were performed with male albino rats (CD strain, Charles River Laboratories, Wilmington, MA, USA). Animals were selected at random for treatment with alloxan monohydrate $(37 \mathrm{mg} / \mathrm{kg}$ body weight) by IV injection into the femoral vein after an overnight fast, while the remainder were used as age-matched controls. All animals were subsequently fed laboratory chow ad libitum. The experiments were performed approximately 2 weeks after the administration of alloxan. Blood glucose values were determined with a Beckman glucose analyzer.

\section{Separation of nucleotides}

The tissues to be studied (liver, kidney, testes, heart and hind limb muscle) were removed rapidly from animals which had been killed by 
Table 1. Effect of diabetes on the levels of sugar nucleotides in several tissues of the rat

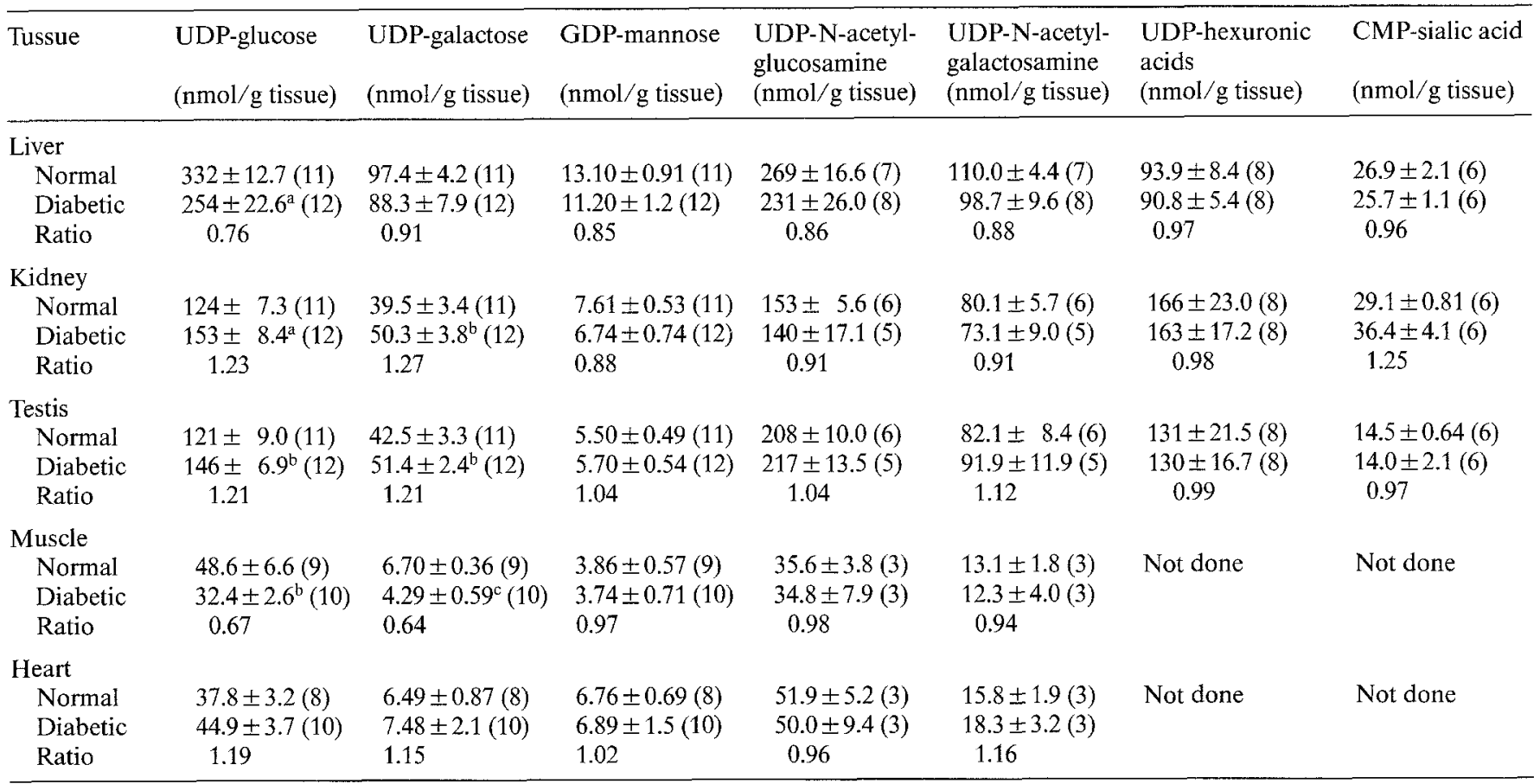

Values are expressed as mean \pm SEM with the number of animals given in parentheses. Significance of difference between normal and diabetic groups: ${ }^{\mathrm{a}} p<0.02 ;{ }^{\mathrm{b}} p<0.05 ;{ }^{\mathrm{c}} p<0.01$

decapitation and were quick-frozen in plastic bags by the use of tongs pre-cooled to $-70^{\circ} \mathrm{C}$ in a dry ice-alcohol bath. Nucleotide extraction was accomplished by pulverizing the frozen tissues, adding five volumes of pre-cooled $70 \%$ ethanol and homogenizing with a Polytron 20ST or 10ST probe (Brinkmann Instruments, Westbury, New York, USA) for two 5-s bursts at a setting of 6 . Before homogenization, ATP was added to the alcohol suspension of the tissue to a final concentration of $0.5 \mathrm{mmol} / 1$ to help protect the nucleotides from enzymatic hydrolysis and $0.05 \mu \mathrm{Ci}(0.2 \mathrm{nmol})$ of UDP- $\left[{ }^{14} \mathrm{C}\right]$ glucose was added as an internal standard to assess recovery of the nucleotides in the individual samples. The homogenates were heated for $3 \mathrm{~min}$ at $100{ }^{\circ} \mathrm{C}$, cooled to $2{ }^{\circ} \mathrm{C}$ and centrifuged at $35,000 \mathrm{~g}$. The pellet was washed once with $60 \%$ ethanol and the volume of the combined supernatant and wash was reduced in a rotary evaporator at $25^{\circ} \mathrm{C}$.

Separation of the nucleotides from free sugars and sugar phosphates was performed by a modification of a technique described previously [14]. The concentrated alcohol extracts from $4 \mathrm{~g}$ or less of tissue were passed through columns of Dowex 50-X4, 200-400 mesh, (Bio-Rad Laboratories, Richmond, California, USA), $\mathrm{H}^{+}$form $(3 \mathrm{ml}$ of packed resin) and washed through with water $(25 \mathrm{ml})$. The effluent and wash were adjusted to $\mathrm{pH} 6.5$ with $\mathrm{NH}_{4} \mathrm{OH}$ and the samples were applied to columns of Dowes 1-X2,200-400 mesh, formate form ( $3 \mathrm{ml}$ of packed resin). After the Dowex 1 columns were washed with $25 \mathrm{ml}$ of water, $60 \mathrm{ml}$ of $4 \mathrm{~mol} / 1$ formic acid was used to remove the sugar phosphates; further treatment with $40 \mathrm{ml}$ of $2 \mathrm{~mol} / 1$ pyridine acetate ( $\mathrm{pH}$ 5.0) eluted the sugar nucleotides as a group.

\section{Analyses of sugar constituents}

Neutral sugars, $\mathrm{N}$-acethylhexosamines and uronic acids were released from their nucleoside pyrophosphate linkage by mild acid hydrolysis $\left(0.1 \mathrm{~N} \mathrm{HCl}, 20 \mathrm{~min}, 100{ }^{\circ} \mathrm{C}\right)$; the neutral sugars and $\mathrm{N}$-acetylhexosamines were recovered in the effluent and wash after passage of the hydrolysates through columns of Dowex 1-X8, 200-400 mesh (formate form). Uronic acids released by the mild acid hydrolysis were recovered from the Dowex 1 column by elution with $3 \mathrm{~mol} / 1$ formic acid.
Neutral sugars were analyzed by means of automated borate anion-exchange chromatography [15] modified to permit detection of sugars in the nmol range. $\mathrm{N}$-acetylhexosamines were determined on the Technicon NC-2 amino acid analyzer (Tarrytown, New York, USA) after release of the acetyl groups by hydrolysis in $1 \mathrm{~mol} / 1 \mathrm{HCl}$ at $100{ }^{\circ} \mathrm{C}$ for $3 \mathrm{~h}$. Both analytical systems contained Hewlett-Packard $3390 \mathrm{~A}$ integrators (Palo Alto, California, USA) for quantifying the results. Uronic acids were examined qualitatively by paper chromatography in pyridine/ethyl acetate/water/acetic acid $(5: 5: 3: 1)$ and only glucuronic acid was observed; quantitative measurement was performed with the carbazole reagent [16].

CMP-sialic acid was isolated by paper chromatography of the alcohol extracts of the tissues in ethanol/ammonium acetate $(1 \mathrm{~mol} / 1)$, pH $7.5(75: 30)$ [17]. Tracer amounts of ${ }^{3} \mathrm{H}$-labelled CMP-N-acetylneuraminic acid were included with each sample to facilitate location of the nucleotide during radioscanning of the chromatogram; the appropriate region of the paper was then excised and eluted with water. Analysis was performed by the thiobarbituric acid reagent [18] without prior hydrolysis [19].

Radiolabelled sugar nucleotides obtained from New England Nuclear (Boston, MA, USA) and unlabelled nucleotides from Sigma (St. Louis, MO, USA) were used to standardize the analytical procedures. Addition of tracer amounts of ${ }^{14} \mathrm{C}$-labelled UDP-glucose to each sample permitted correction for losses of the hexoses or $\mathrm{N}$-acetyl-hexosamines, while recovery of CMP-sialic acid was based on ${ }^{3} \mathrm{H}$ labelled CMP-N-acetyl-neuraminic acid added to the tissue extract before chromatography. No correction was applied to the UDP-glucuronic acid values, since ${ }^{14} \mathrm{C}$-labelled UDP-glucuronic acid was recovered quantitatively.

\section{Enzymatic analysis of UDP-glucose and UDP-galactose}

Measurement of UDP-glucose and UDP-galactose was also performed on several extracts of normal and diabetic liver, kidney and testis by an enzymatic procedure [20]; the ratio of the values determined to those obtained by the chemical technique averaged 1.07 for UDP-glucose and 0.98 for UDP-galactose. The data presented are based on the chemical determinations. 
Table 2. Comparison of the effect of diabetes on metabolites of glucose in tissues of the rat

\begin{tabular}{llllll}
\hline Metabolite & \multicolumn{3}{l}{$\begin{array}{l}\text { Ratio of the concentrations of the metabolite in } \\
\text { diabetic and normal tissue }\end{array}$} \\
\cline { 2 - 6 } & Liver & $\begin{array}{l}\text { Skeletal } \\
\text { muscle }\end{array}$ & Kidney & Heart & Testis \\
\hline $\begin{array}{l}\text { Glycogen } \\
\text { UDP- } \\
\text { glucose } \\
\text { (present }\end{array}$ & $0.058[25]$ & $0.57[26]$ & $2.6[27]$ & $1.4[28]$ & \\
$\begin{array}{l}\text { study) } \\
\text { Glucose 6-P }\end{array}$ & $0.42[25]$ & $0.66[26]$ & $3.1[27]$ & $1.8[28]$ & $1.4[29]$ \\
\hline
\end{tabular}

References from which the data are taken are shown in parentheses

\section{Statistical Analysis}

The results are expressed as mean \pm SEM; statistical analysis was performed by Student's t-test for unpaired samples.

\section{Results}

The diabetic rats had an average blood glucose of $34.2 \pm 1.1 \mathrm{mmol} / 1 \quad(n=12) \quad$ compared with $8.3 \pm$ $0.9 \mathrm{mmol} / 1$ for the normal animals $(n=11)$. Their weight at the time of the experiment averaged $208 \pm 13 \mathrm{~g}$ while that of the normal age-matched animals was $279 \pm 17 \mathrm{~g}$. A comparison of total organ weights indicated the following ratios of diabetic to normal $(\mathrm{g} / \mathrm{g})$ : liver, 0.77 ; kidney, 1.14 ; testis, 0.97 ; and heart, 0.86 .

The concentrations of sugar nucleotides in the normal state differed markedly from one tissue to another, with liver having the highest and muscle and heart the lowest values (Table 1). In each tissue, UDP-glucose and UDP-N-acetylglucosamine were the most abundant compounds; the amounts of these nucleotides present in normal liver was approximately seven times that present in normal muscle. GDP-mannose, on the other hand, was present in the smallest amounts in all tissues and its levels varied over only a threefold range with liver having the most and muscle the least of this nucleotide.

The effect of diabetes on the concentration of the sugar nucleotides was found to depend on the tissue as well as the nucleotide itself. In diabetic liver the UDPglucose was reduced to two-thirds the normal level, whereas the other sugar nucleotides were not significantly affected (Table 1). The decrease in UDP-glucose was even more pronounced in muscle and the UDPgalactose concentration was also substantially diminished, while the remaining nucleotides stayed at normal levels (Table 1).

In kidney and testis, the UDP-glucose and UDP-galactose levels were significantly elevated in diabetes. These two tissues had similar concentrations of all of the nucleotide sugars in the normal state and underwent similar increases in the glucose and galactose nucleo- tides in response to diabetes; however, again as with liver and muscle, the other compounds studied showed no alterations.

Although normal heart had levels of sugar nucleotides similar to those found in normal skeletal muscle, the effect of diabetes on the two types of muscle was quite different, with the diabetic heart having levels of UDP-glucose and UDP-galactose not significantly different from the normal tissue, in contrast to the marked decreases seen in the skeletal muscle of diabetes.

If, instead of comparing nucleotide concentrations the total amounts present in each tissue are considered, the differences observed between normal and diabetic in both liver and kidney are actually amplified. This is so since the weight of the diabetic liver is only threequarters that of normal while diabetic kidney weight is increased. Testis organ weight was essentially unchanged, and in the case of the heart, despite a slight reduction in its weight in diabetes, no significant difference between the normal and diabetic values was observed, when the amounts present in the whole organ were compared.

\section{Discussion}

The present study indicates that, of the sugar nucleotides examined, only UDP-glucose and UDP-galactose undergo important fluctuations in diabetes. The tissues however showed marked differences, with liver and skeletal muscle having decreased levels of these intermediates and kidney and testis showing elevated concentrations. In contrast to skeletal muscle, the levels in heart were unchanged, indicating a dissimilarity between these two types of muscle. Contrasting responses of heart and skeletal muscle in regard to the levels of glucose 6-phosphate, citrate and glycogen have also been demonstrated under conditions of starvation [21].

It has been believed generally that biosynthesis of most of the sugar nucleotides is controlled by feedback inhibition. This was initially demonstrated for UDP-Nacetylglucosamine and CMP-sialic acid formation [22] and more recently for GDP-mannose synthesis [23]. For this reason it is not surprising that the levels of the nucleotides of mannose, the $\mathrm{N}$-acetylhexosamines and sialic acid were not elevated in the tissues included in the present study, but it is noteworthy that they were not decreased in skeletal muscle in which the nucleotides of glucose and galactose were reduced.

In contrast, for UDP-glucose synthesis it has been suggested that feedback inhibition is relatively unimportant and that instead the concentration of the immediate precursor, glucose 1-phosphate, may be the determinant of the nucleotide formation [24]. It is of interest therefore to compare the concentrations of glucose metabolites which have been previously reported for normal and diabetic tissues [25-29] with UDP-glucose levels found in the present study and in turn to re- 
late both of these to glycogen formation by the tissues. A summary of the changes occurring in diabetes in the levels of glucose 6-phosphate, UDP-glucose and glycogen in several tissues is shown in Table 2 and it appears that the alterations in UDP-glucose concentration do indeed reflect those of the precursor, glucose 6-phosphate. In addition, glycogen levels appear to change in a parallel manner. A recent study of placental glycogen synthesis has suggested that the increased formation of this polymer noted in vivo is more clearly reflected by the increased level of substrate present in the tissue (glucose 6-phosphate) than by measurement of the enzymes phosphorylase and glycogen synthese in vitro [30].

The fact that UDP-galactose levels also increase in kidney and testis in diabetes suggests that this nucleotide, like UDP-glucose, also lacks end-product control of its synthesis.

In a recent study by Cortes et al. [31] the UDP-glucose concentration of diabetic kidney was found to be increased to an extent comparable to that found in the present study. In contrast to our findings they found no change in UDP-galactose though elevations were also seen in the nucleotides of the $\mathrm{N}$-acetyl-hexosamines and the hexuronic acids. This difference in results may be explained by the fact that these investigators performed their analyses only $48 \mathrm{~h}$ after induction of diabetes; at this early stage they have previously found increases in several other kidney metabolites, including UDP, all of which declined substantially shortly thereafter [32].

The different responses to diabetes of tissues such as liver and skeletal muscle on the one hand and kidney and testis on the other are clearly seen in Table 2 . Other examples of the unimpaired use of glucose in diabetes have been reported and in fact glucose over-utilization by these and some other tissues has been suggested from the elevated levels of hexokinase and the enzymes of the glycolytic and shunt pathways observed in kidney $[33,34]$ and jejunum [33], from the elevated glycogen content and enzyme levels in placenta [35] and from the increased inositol formation in testis [29].

In relating the findings of the present study to the control of glycoconjugate synthesis in diabetes, it is relevant to compare the concentrations of the sugar nucleotides found in the tissues to the $\mathrm{K}_{\mathrm{m}}$ values of enzymes utilizing these precursors. It has been suggested that glycogen synthesis in the diabetic liver is affected by the failure of this tissue, in the absence of insulin, to convert the $\mathrm{D}$ form of glycogen synthese, which has a high $K_{m}$ value for UDP-glucose $\left(10^{-3} \mathrm{~mol} / \mathrm{l}\right)$ to the I form $\left(\mathrm{K}_{\mathrm{m}}\right.$ of $\left.10^{-4} \mathrm{~mol} / \mathrm{l}\right)$ [36]. Normal liver UDP-glucose levels are in the $10^{-4} \mathrm{~mol} / 1$ range, which is appropriate for the I form of the enzyme, but the decreased level of this nucleotide in diabetic liver would further contribute to the reduced glycogen synthesis noted in this state. On the other hand, synthesis of serum glycoproteins by the liver has been reported to be unaffected by diabetes [12, 13] and in the present study it has been found that the sugar nucleotides required for synthesis of these molecules are maintained at normal concentrations or, in the case of glucose, at adequate levels for the purpose. To evaluate the potential influence of sugar nucleotides on glycoprotein formation, two types of enzymes must be taken into account. For those responsible for the synthesis of the dolichol-linked saccharide intermediates involved in the assembly of the core portion of asparagine-bound carbohydrate units $\mathrm{K}_{\mathrm{m}}$ values of $10^{-7} \mathrm{~mol} / 1$ have been reported for GDP-mannose [37] and UDPglucose [38]; even the very low concentrations of GDPmannose found in the tissues studied and the reduced level of UDP-glucose seen in liver and muscle are many times greater than the $\mathrm{K}_{\mathrm{m}}$ values for the dolichylphosphate monosaccharide synthesis. However, the enzymes involved in building carbohydrate units by adding sugars such as galactose, glucose, sialic acid or $\mathrm{N}$-acetylglucosamine directly from the nucleotides have $\mathrm{K}_{\mathrm{m}}$ values of $10^{-4}$ to $10^{-5} \mathrm{~mol} / 1[17,39,40]$; the $\mathrm{K}_{\mathrm{m}}$ values for sugar nucleotides of enzymes responsible for glycosaminoglycan $[41,42]$ or glycolipid $[43,44]$ synthesis similarly are approximately $10^{-4} \mathrm{~mol} / 1$. Since the tissue concentrations of the nucleotides of these sugars are in the $10^{-4}$ to $10^{-5} \mathrm{~mol} / 1$ range, they are generally not saturating for the enzymes and the rate of glycoconjugate synthesis may depend on substrate availability. When a decrease occurs, as for UDP-glucose and UDP-galactose in skeletal muscle in diabetes, a limitation of glycoprotein or glycolipid synthesis could occur and could contribute to the decrease in mass of this tissue found in this disease.

In contrast, in a tissue like kidney, where an elevation of UDP-glucose and UDP-galactose occurs in diabetes, synthesis of some carbohydrate-containing molecules may be enhanced. These nucleotides are both involved in the formation of basement membrane collagen and increased synthesis of this protein has been demonstrated in the diabetic kidney [2]. Elevated levels of the glycosyl-transferases involved in the formation of the glucosylgalactose disaccharide have also been reported $[3,4,45,46]$. In considering what effect this enhanced glycosylating ability of diabetic kidney might have on basement membrane collagen formation, the question of the importance of the addition of carbohydrate to the peptide chain is relevant. Several recent reports have indicated that, for many newly synthesized proteins, the addition of carbohydrate provides protection against intracellular proteolysis and that molecules not glycosylated turn over more rapidly [47-49]. Degradation prior to secretion has been shown to be an important regulator of fibroblast procollagen production [50]; if basement membrane collagen synthesis is similarly controlled, a higher degree of carbohydration might lead to a greater net production of this protein in diabetes.

Acknowledgements. This project was supported by Grant AM 23009 from the National Institutes of Health; partial funding was also pro- 
vided by Grant BRSG S07 RR 05673 (National Institutes of Health) and by the Adler Foundation, Rye, New York. This study was performed with the excellent assistance of K.M.Gorski and W.C. Fisher, Jr.

\section{References}

1. Spiro RG (1976) Search for a biochemical basis of diabetic microangiopathy. Diabetologia 12:1-14

2. Brownlee M, Spiro RG (1979) Glomerular basement membrane metabolism in the diabetic rat. In vivo studies. Diabetes 28: 121-125

3. Spiro RG, Spiro MJ (1971) Effect of diabetes on the biosynthesis of the renal glomerular basement membrane. Studies on the glucosyltransferase. Diabetes 20: 641-648

4. Bretzel RG, Menden A, Reichardt M, Brocks DG, Draeger KE, Federlin K (1981) Renal collagen glucosyltransferase activity following islet transplantation in streptozotocin-diabetic rats. Diabetologia 21: 428-429

5. Silbert CK, Kleinman HK (1979) Studies of cultured human fibroblasts in diabetes mellitus. Changes in heparan sulfate. Diabetes 28: 61-64

6. Ginsberg LC, Wyse BM, Chang A (1981) Analyses of glycosaminoglycan from diabetic and normal Chinese hamster cells. Diabetes, 30: 393-395

7. Weiss RE, Gorn AH, Nimni ME (1981) Abnormalities in the biosynthesis of cartilage and bone proteoglycans in experimental diabetes. Diabetes 30: 670-677

8. Parthasarathy N, Spiro RG (1982) Effects of diabetes on the glycosaminoglycan component of human glomerular basement membrane. Diabetes 31: 738-741

9. Jonsson A, Wales JK (1976) Blood glycoprotein levels in diabetes mellitus. Diabetologia 12: 245-250

10. Regen TJ, Ettinger PO, Kahn MI, Jesrani MU, Lyons MM, Oldewurtel HA, Weber M (1974) Altered myocardial function and metabolism in chronic diabetes mellitus without ischemia in dogs. Circ Res 35: 222-237

11. Regen TJ, Lyons MM, Ahmed SS, Levinson GE, Oldewurtel HA, Ahmad MR, Haider B (1974) Evidence for cardiomyopathy in familial diabetes mellitus. J Clin Invest 60: 885-899

12. Spiro RG (1959) Role of insulin in two pathways of glucose metabolism: in vivo glucosamine and glycogen synthesis. Ann NY, Acad Sci 82: 366-373

13. Berry EM, Ziv E, Bar-On H (1980) Protein and glycoprotein synthesis and secretion by the diabetic liver. Diabetologia 19: $353-540$

14. Adamany AM, Spiro RG (1975) Glycoprotein biosynthesis: studies on thyroid mannosyltransferases. I. Action on glycopeptides and simple glycosides. J Biol Chem 250: 2830-2841

15. Spiro RG, Spiro MJ, Bhoyroo VD (1976) Lipid-saccharide intermediates in glycoprotein biosynthesis. II. Studies on the structure of an oligosaccharide-lipid from thyroid. J Biol Chem 251: 6409-6419

16. Dische Z (1947) A new specific color reaction for hexuronic acid. J Biol Chem 167: 189-198

17. Spiro MJ, Spiro RG (1968) Glycoprotein biosynthesis: studies on thyroglobulin. Thyroid sialyltransferase. J Biol Chem 243: $6520-6528$

18. Warren L (1960) The thiobarbituric acid assay of sialic acids. J Biol Chem 234: 1971-1975

19. Aminoff D (1961) Methods for the quantitative estimation of $\mathrm{N}$-acetyl neuraminic acid and their application to hydrolysates of sialomucoids. Biochem J 81: 384-392

20. Keppler D, Rudigier J, Decker K (1970) Enzymatic determination of uracil nucleotides in tissue. Anal Biochem 38: 105-114

21. Ruderman NB, Goodman MN, Conover CA, Berger M (1979) Substrate utilization in perfused skeletal muscle. Diabetes 28 (Suppl 1): 13-17
22. Kornfeld S, Kornfeld R, Neufeld EF, O'Brien PJ (1964) The feedback control of sugar nucleotide biosynthesis in liver. Proc Natl Acad Sci USA 52: $371-379$

23. Mendicino J, Rao AK (1975) Regulation of the synthesis of nucleoside diphosphate sugars in reticulo-endothelial tissues. Eur J Biochem 51: $547-556$

24. Roach PJ, Warren KR, Atkinson DE (1975) Uridine diphosphate glucose synthase from calf liver: determinants of enzyme activity in vitro. Biochemistry $14: 5445-5450$

25. Start C, Newsholme EA (1968) The effects of starvation and alloxan-diabetes on the content of citrate and other metabolic intermediates in rat liver. Biochem $\mathrm{J}$ 107: 411-415

26. Goodman MN, Berger M, Ruderman NB (1974) Glucose metabolism in rat skeletal muscle at rest. Effect of starvation, diabetes, ketone bodies and free fatty acids. Diabetes $23: 881-888$

27. Needleman P, Passonneau JV, Lowry OH (1968) Distribution of glucose and related metabolites in rat kidney. Am J Physiol 215: 655-659

28. Mansford KRL, Opie L (1968) Comparison of metabolic abnormalities in diabetes mellitus induced by streptozotocin or alloxan. Lancet 1: 670-671

29. Rancour TP, Wells WW (1980) myo-Inositol metabolism in rat testis in response to streptozotocin-induced diabetes. Arch Biochem Biophys 202: 150-159

30. Barash V, Gutman A, Shafrir E (1983) Mechanism of placental glycogen deposition in diabetes in rat. Diabetologia 24: 63-68

31. Cortes P, Dumler F, Sury Sastry KS, Verghese CP, Levin NW (1982) Effects of early diabetes on uridine diphospho sugar synthesis in the rat renal cortex. Kidney Int 21:676-682

32. Cortes P, Levin N, Dumler F, Rubenstein AH, Verghese CP, Venkatachalam KK (1980) Uridine triphosphate and RNA synthesis during diabetes and renal growth. Am J Physiol 238: E349-357

33. Anderson JW, Stowring K (1973) Glycolytic and gluconeogenic enzyme activities in renal cortex of diabetic rats. Am J Physiol 224: 930-936

34. Sochor M, Baquer NZ, McLean P (1979) Glucose overutilization in diabetes: evidence from changes in hexokinase, the pentose phosphate pathway and the glucuronate-xylulose pathway in rat kidney cortex in diabetes. Biochem Biophys Res Commun 86: 32-39

35. Diamant YZ, Shafrir E (1978) Placental enzymes of glycolysis, gluconeogenesis, and lipogenesis in the diabetic rat and in starvation. Diabetologia 15: 481-485

36. Bishop JS, Larner J (1967) Rapid activation-inactivation of liver uridine diphosphate glucose-glycogen transferase and phosphorylase by insulin and glucagon in vivo. J Biol Chem 242: 1354-1356

37. Adamany AM, Spiro RG (1975) Glycoprotein biosynthesis: Studies on thyroid mannosyltransferases. II. Characterization of a polyisoprenyl mannosyl phosphate and evaluation of its intermediary role in the glycosylation of exogenous acceptors. $J$ Biol Chem 250: 2842-2854

38. Scher MG, Jochen A, Waechter CJ (1977) Biosynthesis of glucosylated derivatives of dolichol: possible intermediates in the assembly of white matter glycoproteins. Biochemistry 16: 5037-5044

39. Spiro RG, Spiro MJ (1971) Studies on the biosynthesis of the hydroxylysine-linked disaccharide unit of basement membrane and collagen. III. Tissue and subcellular distribution of the glycosyltransferase and the effects of various conditions on the enzyme levels. J Biol Chem 246: 4919-4925

40. Spiro MJ, Spiro RG (1968) Glycoprotein biosynthesis: Studies on thyroglobulin. Thyroid galactosyltransferase. J Biol Chem 243: 6529-6537

41. Helting T, Roden L (1969) Biosynthesis of chondroitin sulfate. I. Galactosyl transfer in the formation of the carbohydrate-protein linkage region. J Biol Chem 244: 2790-2798

42. Helting T, Roden L (1969) Biosynthesis of chondroitin sulfate. II. Glucuronosyl transfer in the formation of the carbohydrate protein linkage region. J Biol Chem 244: 2799-2805

43. Basu S, Kaufman B, Roseman S (1973) Enzymatic synthesis of glucocerebroside by a glucosyltransferase from embryonic chicken brain. J Biol Chem 248: 1388-1394 
44. Basu M, Basu S (1972) Enzymatic synthesis of a tetraglycosylceramide by a galactosyltransferase from rabbit bone marrow. J Biol Chem 247: 1489-1495

45. Chang AY, Noble RE, Perry CS, Greenberg HS (1980) Renal glucosyltransferase activity in highly-inbred spontaneously diabetic Chinese hamsters. Diabetologia 19: 40-44

46. Pihlajaniemi T, Myllylä R, Kivirikko KI, Tryggvason K (1982) Effects of streptozotocin diabetes, glucose and insulin on the metabolism of Type IV collagen and protegolycan in murine basement membrane-forming EHS tumor tissue. J Biol Chem 257: 14914-14920

47. Olden K, Pratt RM, Yamada YM (1978) Role of carbohydrates in protein synthesis and turnover: effects of tunicamycin on the major cell surface glycoprotein of chick embryo fibroblasts. Cell 13: 461-473

48. Gahmberg CG, Jokinen M, Karki KK, Andersson LC (1980) Effect of tunicamycin on the biosynthesis of the major human red cell sialoglycoprotein, glycophorin $A$, in the leukemia cell line K 562. J Biol Chem 255: 2169-2175
49. Prives JM, Olden K (1980) Carbohydrate requirement for expression and stability of acetylcholine receptor on the surface of embryonic muscle cells in culture. Proc Natl Acad Sci USA 77: 5263-5267

50. Tolstoshev P, Berg RA, Rennard SI, Bradley KH, Trapnell BC, Crystal RG (1981) Procollagen production and procollagen messenger RNA levels and activity in human lung fibroblasts during periods of rapid and stationary growth. J Biol Chem 256: $3135-3140$

Received: 3 May 1983

and in revised form: 27 July 1983

Dr. Mary Jane Spiro

Joslin Research Laboratory

1 Joslin Place

Boston, MA 02215

USA 